\title{
Challenges Faced by a Sports Woman in Pakistani Society
}

\author{
A. Gul (Ayesha Gul)', 5. Jahangig (Shagufta Jahangir)², M. Nadeemullah \\ (Mohammad Nadeemullah)3 ${ }^{3}$ R. Changezi (Rahim Changezi) ${ }^{4}$, A. Naz (Arab Naz)
}

1 Social Work Deptt. SBK Women's University Quetta, Pakistan.

\section{Original Article}

2 Scholar Karachi University. Sindh Pakistan.

3 Karachi University Sindh, Pakistan.

4 Social Work Deptt. University of Balochistan, Pakistan.

${ }_{5}$ Malakand University. Dir Khyberpakhtunkhwa, Pakistan

\section{E-mail address:}

gul_aisha@hotmail.com

\section{Reprint address:}

Ayesha Gul

Social Work Dept. SBKWU University Balochistan

Bawrery Road, Quetta

Balochistan

Pakistan

Source: Clinical Social Work and Health Intervention Volume: $10 \quad$ Issue: 4

Pages: Cited references: 11

\section{Reviewers:}

Gabriela Lezcano

University of California, San Francisco, USA

Zofia Szarota

Pedagogical University of Cracow, Poland

\section{Keywords:}

Sportswomen. Social Behavior. Subordinate. Human Rights. Gender Discrimination.

\section{Publisher:}

International Society of Applied Preventive Medicine i-gap

CSWHI 2019; 10(4): 42 - 48; DOI: 10.22359/cswhi_10_4_03 ( 2019 Clinical Social Work and Health Intervention

\section{Abstract:}

In many societies sports are considered as an inappropriate activity for women as it is traditionally associated with masculinity. The aim of this study is to critically analyze the social issues and challenges of 
sportswomen in Pakistan. Non-probability sampling for data collection was used and for this purpose, snowball sampling and purposive sampling techniques were applied. The interview schedule is utilized as a tool where 210 sportswomen were approached and had structured and unstructured interviews for having knowledge about their personal qualities and skills of sportswomen. The results of this study highlights that due to social norms, values, customs, culture, myths, traditions, unstable economic conditions and erroneous religious women outlook are not able to participate in sports activities while, sports activities can provide a channel to educate women about their communal, legal and physical rights along with productive and reproductive rights.

\section{Introduction}

The current scenarios of developing nations, the human capital is weak as underdeveloped nations are spending less on education and health then how could they spend for entertainment purpose. In addition, mostly societies are traditional and have different gendered expressions for male and female. So, these socially constructed roles create gender disparities in all segments of life, however in that long list of discriminations I have observe a little circle of women who are playing sports. Later I searched more about specific sportswomen sample, which was a difficult part of research, but that time I saw women sports federation which developed huge interest for the researcher to observe their lifestyle and social status in existing societies. On that basis, objectives and research questions were designed to gauge the actual status of sportswomen in Pakistani society.

In developing world the concept of women and sports not fully establish, it still needs further exploratory because of the changing socio-economic status of the women in the world. Whereas if we look up for previous researches on women and sports, international researches have been found so far, and elaborated that in Iran traditional beliefs of gender segregation have been changing for instance under strict veiling policies, women are playing sports after seeing other female athletics as role model in such scenario parents confidence restored and sending female children to various sports including judo, karate, taekwondo, shooting, mountain climbing and rowing.

On the other hand if we look up on India's situation, it is a secular state there are no problem of veil or any other social restriction but problem for women in sports are differing from other countries as females use to play from their early school and college but later they have to give up, because non-availability of play grounds, coaches or mentors, and of course the equipments or goods required for specific games. Due to the reason male in sports are recognized, even fantasized in the world but female's inclusion is at inborn stage (Sengupta, 2018). Similarly, Pakistan is also a male dominant society and facing sexual division in all segments of the society, so this paper aims to acknowledge the role of sportswomen in the society as females found playing various sports; this research is highlighting the role of patriarchy and male dominant factors on lives of sportswomen.

It is further finding the barriers including attire and costumes, sexual harassment, hierarchy, and also analyzing the role of media. These mentioned factors are observed to acknowledge the social status of sportswomen in Pakistani society. However, it is observed that in developed nation that fe- 
males who are playing sports are more confident and have high self-esteem. As women are involved in sports related activities from childhood, because of the reason they have good physique and higshest psychological wellbeing and free from all sort of depressions. If we practice sports for women in Pakistan women become more empowered, their personality enhance, better health, and of course stable financially. Women in sports activities are marginal in Pakistan; the government should provide incentives to sportswomen in order to encourage females for playing sports to become strong in the society.

\section{Literature Review}

After inception of Pakistan in 1947, politics and economy were the major focused areas for the development. Later sports and Olympics had begun momentum in the country, so this was the time where women were only the spectators of sports. However, few females were playing at school or college levels, all sports related activities were halted and strictly forbidden for women in Pakistan during the Martial Law regime (1977-1986) (Asian Development Bank, 2007).

It is concluded that there are few widely known positive role models of sports women are present in the world. According to (Waqar, 2018) the lack of known role models, female participation has not been increasing with faster pace, as social media is also keeping Pakistan's youth specially young females away from sports. In Pakistan very limited women become in the position of role models and coaches in sports, for instance coach (Sabiha Azhar), Football (Sadia Shaikh \& Fouzia Naz) but in individual sports (badminton, tennis, martial art) not a single female recognized as famous coach in present scenario of Pakistan.
Recently, we have found one example Sara Mansoor (tennis player) announced as first tennis coach in Pakistan. Besides all social, religious and economic problems the brave Pakistani young sportswomen Raheela Zameen (footballer) has the honor to become a first female South Asian coach of a professional men's team but still there are lack of opportunities, as they do not enter in the field of sports while, they proved their determination and showed that their passion for sports is not less than that of men. In this regard, government and sports departments should promote the participation of women in sports and provide them space to explore their talents because sports activities will helpful in promote peace and harmony in the region (Jazbey, 2018).

Moreover, if we talk about current female players, Sana Mir and Javeria Khan have been known as number one in bowling and booker berth in the ICCI Women's World T20 in 2018, this triumph also uplift the status women players but also represented a good picture of Pakistani society at international level (The Nation, 2018). Another example, a two-time Academy Award winner Sharmeen Obaid-Chinoy's latest collaboration with HBO SPORTS (A private TV Channel) for a documentary on 'STUDENT ATHLETE', which has been nominated for the 2019 NAMIC Vision Awards by National Association for Multi-Ethnicity in Communications. The awards recognize original programming of the documentary that reflected lives, spirit and contributions of people of color that best reflects the ethnic and cultural diversity of the viewing audience. The film making on sports subject shows that now researchers director or film makers are working on the subject to display hided segments of the society on motion picture in order to increase the audiences for encouraging women and sports related activities. 


\section{Methodology}

Research is followed by snowball sampling technique of non-probability sampling. The researcher has used structured and semi-structure interview techniques in the study. Almost questions are open ended to find out the basic obstacles of the society which hinder the women to participate in sports activities. The tool of measurement is simple chi-square technique used by researcher. The sample of the study is comprised of 210 sports women, to approach these women, various sports federation visited to get sports women respondents for collecting primary data. ciety. Similarly, if we look up on sports related activities among men and women, so it is considered that women are inferior to men and cannot compete equivalent to men due to lower strength and speed. Whereas, it is medically explained that women have greater flexibility, body mass with fats and small body size which would highly advantageous while play sports. It can be said that women can perform much better as good as men for instance in running series; synchronized swimming; in horse racing; or even can prove themselves footballs game and rugby. It is regarded as people have created a mind sets.

\section{Social, Religious and Economical Issue of Sports Women in Pakistani Society.}

\begin{tabular}{|l|c|}
\hline Federation's Name & Number of Sample \\
\hline Pakistan Cricket Board & 35 \\
\hline Pakistan Hockey Federation & 27 \\
\hline Pakistan Football Federation & 23 \\
\hline Pakistan Tae Kwando Martial Art Federation & 15 \\
\hline Pakistan Table Tennis Federation & 10 \\
\hline Pakistan Badminton Federation & 13 \\
\hline Pakistan Squash Federation & 03 \\
\hline Chess Federation of Pakistan & 05 \\
\hline Athletics Federation of Pakistan & 29 \\
\hline Sind Women Swimming Association & 26 \\
\hline Pakistan Tennis Federation & 05 \\
\hline Pakistan Golf Federation & 02 \\
\hline Alpine Club of Pakistan (Mountain Climber) & 02 \\
\hline Pakistan Weight Lifting Federation & 03 \\
\hline Pakistan Scuba Diving Association & 02 \\
\hline Indus Scuba Pakistan & 10 \\
\hline
\end{tabular}

\section{Results And Discussion}

Pakistan has very unique geography with having various cultures and traditions, which exists in form of sub-societies. However, the beliefs are saturated from one society to another society because of associated myths. The myths are prevailing since ages due to lack of education and socio-cultural misleading behaviors and trends in the so-
According to the available facts, at school and colleges levels funds allocations are very limited and in such scenario male students enrolled more as compared to female students. This is the point when discrimination started and spent funds unequally among both the sexes. In fact in Pakistani society, patriarchs believed that issues on women in sports are irrelevant and have no importance 
rather academician or researchers should focus on labor force participation and political empowerment. So, this the point where the researcher had brainstormed that sports and athletes can have positive role in women's leadership development in almost all segments, which could definitely enhance their social status.

The findings of the existing paper revealed significant, strong relationship among sports activities and socially constructed values, myths, tradition and culture. Although the Pakistani women are very strong, tough, active and talented as other women's of the world, but these societal attitudes create the obstacles for women participation in sports activities. According to previous researches it was marked that the lower participation of women in sports is only because of associated myths that women cannot play, considered bad whereas; majority of sportswomen in the current research informed that culture and tradition is not obstacle but close relatives and male dominancy in family structures are mainly held responsible for this discrimination (Javed, 2014;Burch et al, 2014, McKay, 2013; Berberick, 2010).

It is also a ground reality that women participation has been increased as compared to the past years but situation remain same as societies still do not consider sports as an activity for women. Sport is a very prominent social institution in almost all the societies around the world it conventionally connected with masculinity while, many western sociologists and feminists declared that sports emulate the society, the shimmering values, myths, customs and social norms of the society. It works for progressive society whereas, the present societies categorically classify sports as feminine or masculine, but still we see that all sports are considered to be for men specifically. Many feminist social theories determined that gender discrim- ination in sports is very common while a myth is, women lose their femininity and their physical appearance and resembles like men. These kind of believing paradigms are creating hurdles in sportswomen lives and further discourage female youth to become a sports person.

Gender balanced global sports report finds out, that only cricket is raising their profile by increasing sponsorship opportunities, ground audiences and TV coverage in Australia, England, Wales and India since last decade (Bailey, 1993). Pakistan and South Africa are also included in this list, and it is also observed that female cricketers who are financially stable have a sound position to play sports professionally throughout the year as compared to other individual and team events. Sports can help Pakistani women to get empowered and will also help in personality building along with controlling health issues and last but not the least will bring economic stability among women. While interviewing sportswomen, shared that they feel themselves insecure because the society does not take women into decision making process in any of event or life occurrence. However; sport is a healthy activity which provides grounds for ideological thinking and for developing better gender relations. Research findings showed that it is very important to aware the society about the health benefits of the sport activities and its importance in developing healthy society and for leading a healthy life.

Meanwhile, scholars explored that women can change their state by their own, through breaking all social barriers while urged concerned government departments to provide them basic necessities for example education, technical and vocational trainings, strengthen labor force in order to make themselves dominant in the society as men, then it is expected that mind sets could be changed especially of parents, families, 
schools, colleges, teachers and administrators of that particular area or region (Devi, 2017). It is observed by Indian researchers that while female players taken trainings under coaches or mentors, they faced harassments, as misbehaved and many have been caught in love affair. It can be said that such scenario restricting female to get into sports, as there are many cases in which female player terminated from tournaments instead of culprits i.e. coaches (Ahmad, 2015).

Pakistani government need to revise their policies regarding women's sports, because some individual sports need immediate action for their stability. Women in sports activities are marginal in Pakistan, which is already elaborated above in detail, i.e. due to the variety of factors they get fewer chances for participating fully and independently in sports. A strong sports system supports positively and holds women equitably, is essential for empowerment of Pakistani women in sports. As a developing country and global economic environment, it is informed by women respondents, "We are ready for the highly competitive workplace and can change family life through sports." To evaluate the status of sports women in the society, this study aims to explore the concept of women and sport by comparing the social barriers and the status of women in the society.

In fact, it is the responsibility of the sports federation, federal and provincial governments to give incentives and benefits to women/girls for participation in national and international sport events. These institutions are also responsible for providing experienced female coaches, complete medical facility, and positive competitive environment and job opportunities to sportswomen in a way to secure their futures. Whereas, it is observed, there is a scarcity of playgrounds and clubs spe- cifically for women in Pakistan. Society as well as parents does not allow their daughters to play with men at any stage and any sports, because mingling with men is not considered unethical. Though, government does not take any positive action for the improvement of women's sports, there must be proper policy making for sportswomen to promote sport culture among women. It is unveiled by the women players that government should provide protection to women against gender discrimination, ethnicity, and prevailing class system in the society to promote women in sports.

\section{Conclusion}

Pakistani sports women have much potential than other sports women in the world. They are iconic in the women's sports world. Unfortunately, they face many social and cultural problems to show their talent in the world. Results reflecting that society have to be changes to decline the pathetic social structure of Pakistani society, which decline the position of women in the society by all means including sports because sports activities boost up the women physically, mentally and psychology. The role of women in policy making as well as in decision making process is not seen anywhere so the future of sports women in Pakistan seems very insecure. Sport is a healthy activity which provides grounds for ideological thinking and for developing better gender relations. Research findings clearly describe that it is very important to aware the society about the health benefits of the sport activities and its importance in developing healthy society and leading a healthy life. More researches have to be done in future in this regard which bring insight about the sport activity and aware the society about the significance of sports in building a positive and healthy environment. 


\section{References:}

1. AHMAD A H (2015) Women sports in India-Constraints, Challenges, complications, and its remedies, International Journal of Applied Research 1(13): 656-659.

2. ASIAN DEVELOPMENT BANK (2007) Country Briefing Paper. Women in Pakistan. Programs Department (West) and Office of Environment and Social Development.

3. BAILEY N (1993) 'Women's sport and the feminist movement building bridges', in Cohen, G. (Ed) Women in Sport. Issues and Controversies. Thousand Oaks, CA: Sage, 297-304.

4. BERBERICK S N (2010) The objectification of women in mass media: Female self-image in misogynist culture. The New York Sociologist, 5, 1-15.

5. BURCH L M, CLAVIO G, EAGLEMAN A N, MAJOR L H, PEDERSEN P, FREDERICK E L, BLASZKA M (2014) Battle of the sexes: Gender analysis of professional athlete tweets. Global Sport Business Journal, 2(2), 43-62.
6. DEVI M (2017) Women's Participation In Sports In India, Kaav International Journal Of Economics, Commerce \& Business Management A Refereed Blind Peer Review Quarterly Journal Kijecbm, Jan-Mar (2018), Vol-5(1), P (54-56).

7. JAVED N (2014) Meanings, patterns and the social function of hijab amongst female university students. European Academic Research, 1(12), 5499-5510.

8. JAZBEY J (2018) Females in Sports for Peace and Tolerance, Retrieved Febuary from https://crss.pk/story/sabawoon-showcase-jwandai-jazbey-september-26-2018.

9. MCKAY T (2013) Female self-objectification: Causes, consequences and prevention. McNair Scholars Research Journal, 6(1), 53-70.

10. SENGUPTA D (2018) Women's sports in India. Retrieved from https://womennow.in/ womens-sports-in-india/.

11. THE NATION (2018) Retrieved from https://nation.com.pk/01-Jan-2019/javeria-sana-dominate-pak-women-cricket-in-2018. 